\title{
sciendo
}

\section{INCREASED INCIDENCE AND ANTIMICROBIAL RESISTANCE AMONG VIBRIO PARAHAEMOLYTICUS IN SHELLFISHES FROM MAJOR FISH MARKETS IN COCHIN, SOUTH INDIA: SEAFOOD RISK ASSESSMENT}

\author{
Reshma Silvester ${ }^{1 \bullet}$, Amala Saji², Anagha Rani Divakaran², Dilshana P.M. ${ }^{2}$, Radha Nair $^{2}$, Mohamed Hatha ${ }^{3}$, Harikrishnan M. ${ }^{1}$ \\ ${ }^{1}$ School of Industrial Fisheries, Cochin University of Science and Technology (CUSAT), Lakeside Campus, Kochi, 682016, India \\ ${ }^{2}$ MES College for Advanced Studies, Edathala, Kerala, 683564, India \\ ${ }^{3}$ Department of Marine Biology, Microbiology and Biochemistry, Cochin University of Science and Technology (CUSAT), Lakeside Campus, \\ 682016, India \\ •Corresponding author: sanasilvester@gmail.com \\ ORCID ID: 0000-0001-6182-6031
}

\begin{abstract}
India remains as a top supplier of value-added seafoods to the global markets. Cochin is one of the leading fishing ports in India contributing to country's major seafood export. As part of risk assessment, we analyzed the prevalence of multi-drug resistant Vibrio parahaemolyticus, seafood borne gastroenteritis-causing pathogen, in shellfishes collected from major fish markets in Cochin. This bacterial species was initially isolated on thiosulfate-citrate-bile salts-sucrose agar and HiCrome ${ }^{\mathrm{TM}}$ Vibrio agar, further confirmed by detection of $V$. parahaemolyticus species-specific tox $R$ gene and by $16 \mathrm{~S}$ r RNA sequencing. A total of 113 confirmed V. parahaemolyticus were recovered. Almost all the strains exhibited resistance towards three or more antibiotics (multiple-drug resistant) and harbored virulence related exoenzymes especially hemolysin (Kanagawa phenomenon), which is indeed a matter of concern. The multiple antibiotic resistance (MAR) index of the isolates ranged from 0.21 to 0.57. Furthermore, our results also indicate a substantial increase in the incidence of the pathogen in seafood from the area compared to previous years. This may pose a risk to the local and international consumers of the seafood. Practicing complete hygiene and adequate cooking is strongly recommended. Regular monitoring of aquaculture areas and fish markets is urged to reduce dissemination of pathogenic V. parahaemolyticus in seafood and to prevent fatal cases of human infection induced by this species in the country.
\end{abstract}

Abstract

Key words: V. parahaemolyticus, seafood, risk assessment, antimicrobial resistance, India

Indian fisheries and aquaculture is an important food sector providing nutritional security, besides livelihood support and gainful employment to more than 14 million people of the country (Dash et al., 2020). Besides, fish and fish products form the largest group in agricultural exports from India and constitute the major protein source of the country. Fisheries has a major role in India's food export basket contributing to $49 \%$ of animal product exports from the country (Statistical Year Book India, 2017). The Kerala state of India is abundantly rich with marine, brackish water and fresh water resources. The State with a long coast line is a significant contributor to the total marine fish landings of the country and a major seafood exporter from the country (Kulkarni, 2005).

One of the major threats to the Indian fishery sector is the bacterial contamination of the seafood and presence of prohibited drugs; leading to rejection of tons of export consignment each year (Henson et al., 2004).

Among the various diseases, vibriosis caused by pathogenic Vibrio spp. is the most common which has led to mass mortality among fish and shellfish in Asian countries (Ananda Raja et al., 2017 a, b, c; Ina-Salwany et al., 2019). Shellfish and other aquatic organisms are frequently associated with pathogens such as Vibrio parahaemolyticus and they are known as vehicles for the transmission of this bacterium (Malcolm et al., 2015; Yu et al., 2016; Ananda Raja et al., 2017 a, b). Ingestion of seafood contaminated with $V$. parahaemolyticus may lead to seafood-borne gastroenteritis, and the common symptoms include watery diarrhea, abdominal cramps, nausea, vomiting, fever, headache and/or bloody diarrhoea (Humphries and Linscott, 2015; Ananda Raja et al., 2017 a).

The major factors involved in pathogenicity of V. parahaemolyticus are thermostable direct haemolysin (TDH) and TDH-related haemolysin (TRH) (Honda et al., 1987 a, b). However, absence of $t d h$ and $t r h$ was reported in clinical strains of $V$. parahaemolyticus (Pazhani et al., 2014). This suggests that pathogenicity of this bacterium is rather complex and involves multiple factors.

India is the leading antibiotic consumer in the world closely followed by China and the USA (Van Boeckel et al., 2014) and is also one among the top five consumers of antimicrobials in food animals. Antibiotics are widely 
used by Indian farmers to control and treat diseases. Tetracycline, quinolones, oxytetracycline, trimethoprim and sulphonamides are among the antibiotics commonly used in the Asian aquaculture industry (Rico et al., 2012; Yano et al., 2014). The unnecessary or overuse of antibiotics in aquaculture sector results in the emergence of multi-drug resistant 'superbugs' and the dissemination of the antibiotic-resistant genes in the environment. It also leads to accumulation of antibiotic residues in aquatic organisms such as fish (Miranda et al., 2018).

The unsustainable practices have taken the aquaculture industry on a rollercoaster ride, bringing it close to collapse. The present situation is such that the world is running short of effective drugs for critical treatments. If not dealt seriously, this could lead to a post-antibiotic era where people will start dying even due to simple bacterial infections. Hence, regular surveillance and reporting of antibiotic resistance is particularly important.

In India drug-resistant infections are the highest in the world (Laxminarayan and Chaudhury, 2016). Every year, many pathogenic Vibrio spp. are reported to develop high degree of resistance to many clinically important antibiotics (Letchumanan et al., 2015). The increasing emergence and spread of antibiotic-resistant $V$. parahaemolyticus strains is a matter of major concern in many countries (Ahmed et al., 2018; Elmahdi et al., 2016; Letchumanan et al., 2014).

The consumption of seafood contaminated with these multi-drug resistant pathogens can cause serious health risks for the consumers. Seafoods are among the major commercially valuable food items for local and export trade. Previous study has reported incidence of the pathogen in seafood from Cochin market, India (Sudha et al., 2014). However, regular monitoring is required to look for any increasing trend in the prevalence of the pathogen so as to ensure public health safety.

Taking into consideration the epidemiological importance of $V$. parahaemolyticus and seafood risk assessment, the present study aimed to verify antibiotic susceptibility and virulence factors among $V$. parahaemolyticus isolated from shellfishes commercialized in the major fish markets in Cochin, South India.

\section{Material and methods}

\section{Sampling}

Shrimp and crab samples $(n=21,21)$ were collected from three major fish markets (Munambam, Varapuzha and Thoppumpady) in Cochin located in Kerala, South India. The map displaying the location of the study area is shown in Figure 1. High prevalence of V. parahaemolyticus is usually reported during the summer months. Hence, sampling was conducted during the summer of May, 2019. The samples (whole; 7 samples of shrimp/ crab from each location) were collected aseptically in sterile ziplock bags and transported to the laboratory in an icebox.

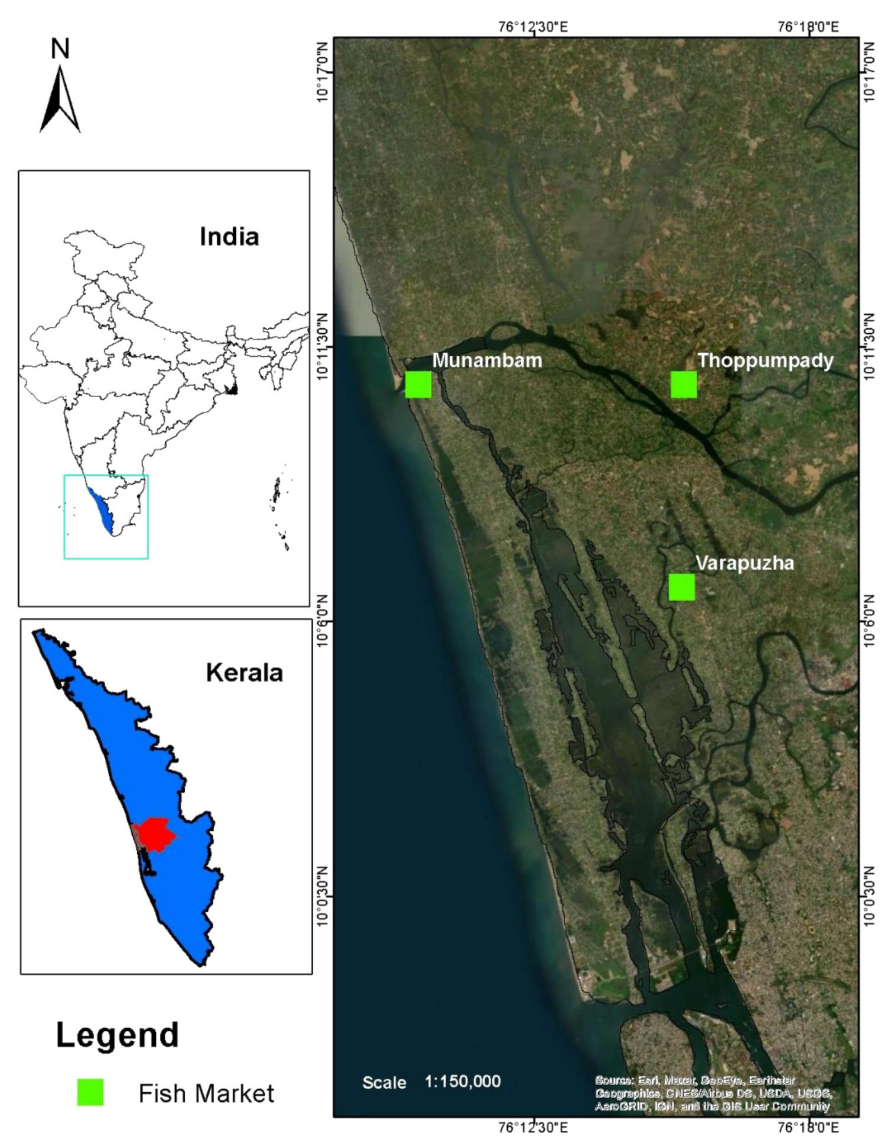

Figure 1. Map showing the details of the study locations 
Sample processing and enrichment

All samples were processed within 4 hours after the collection. Samples were washed thoroughly with sterile normal saline prior to bacteriological examination. The whole of shrimps and flesh from the main body part of crabs were blended in a stomacher. For enrichment, $25 \mathrm{~g}$ of the sample was added to $225 \mathrm{ml}$ of alkaline peptone water (APW) and incubated at $37^{\circ} \mathrm{C}$ for $18-24$ hours for isolation of $V$. parahaemolyticus (Ananda Raja et al. 2017 a).

Isolation and identification of $\boldsymbol{V}$ parahaemolyticus

A loopful of enrichment broth was aseptically streaked onto sterile surface dried thiosulphate citrate bile salt sucrose (TCBS; Himedia, India) agar plates, and incubated overnight at $37^{\circ} \mathrm{C}$. About $3-4$ colonies having a green or bluish-green colour were picked from each TCBS plate (Atlas and Snyder, 2013). The preliminary identification of Vibrio species was performed using Gram staining, oxidase test and oxidative-fermentative test as previously described (Silvester et al., 2015).

A total of 158 presumptive Vibrio isolates (Gram negative, oxidase positive and fermentative without gas production) were obtained from TCBS agar. These isolates were streaked onto a chromogenic medium for further confirmation (HiCrome ${ }^{\mathrm{TM}}$ Vibrio agar, Himedia). The isolates producing species-specific bluish-green colonies on HiCrome ${ }^{\mathrm{TM}}$ Vibrio agar (Supplementary Figure 1) was considered as $V$. parahaemolyticus as previously described (Silvester et al., 2015). The colonies were maintained on nutrient agar slants supplemented with $3 \%$ $\mathrm{NaCl}$ for further identification.

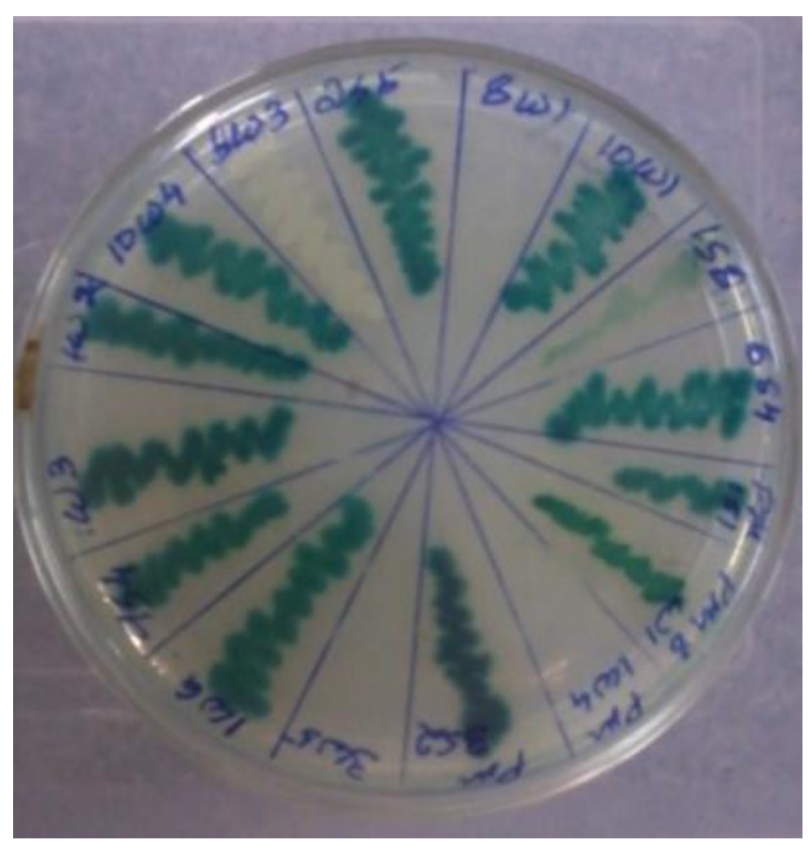

Supplementary Figure 1. HiCrome ${ }^{\mathrm{TM}}$ Vibrio agar plate showing V. parahaemolyticus specific (bluish green colour) and non-specific colonies
Molecular confirmation of $\boldsymbol{V}$. parahaemolyticus

The presumptive $V$. parahaemolyticus isolates obtained from HiCrome ${ }^{\mathrm{TM}}$ Vibrio agar were further subjected to molecular confirmation. Chromosomal DNA from the isolates was extracted by the boiling method (Devi et al., 2009). Isolated DNA was used for molecular confirmation by PCR amplification of $V$. parahaemolyticus specific tox $R$ gene (forward 5'-GTCTTCTGACGCAATCGTTG-3' and reverse 5'ATACGAGTGGTTGCTGTCATG-3') using the protocol by Kim et al. (1999). The isolates that gave positive amplification for species-specific tox $R$ gene (368 bp) (Supplementary Figure 2) were confirmed as $V$. parahaemolyticus.

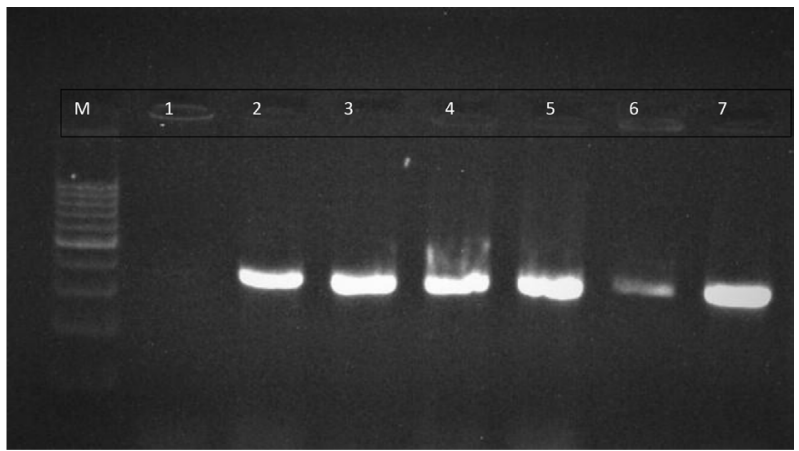

Supplementary Figure 2. Agarose gel displaying $V$. parahaemolyticus specific toxR (368 bp) gene PCR products. Lane M: 100 bp DNA ladder; lane 1: negative control lanes 2-7: V. parahaemolyticus isolates

A representative strain TC7 was further confirmed by 16S r RNA gene sequencing using the primer set (forward: 5'-AGAGTTTGATCCTGG CTCAG-3', reverse: 5'-GGTTACCTTGTTACG ACTT-3') following the protocol previously described (Silvester et al., 2015). The 16S r RNA gene sequence of TC7 was deposited in the NCBI Genbank and an accession number MW326758 was obtained.

\section{Antibiotic sensitivity test}

The antibiotic sensitivity of the $V$. parahaemolyticus isolates was screened using the disc diffusion method (Bauer et al., 1996). A total of 113 strains of $V$. parahaemolyticus isolated from shrimp and crab samples were screened. These included strains isolated from $\mathrm{Mu}-$ nambam $(\mathrm{n}=27)$, Varapuzha $(\mathrm{n}=58)$ and Thoppumpady $(n=28)$. Antibiotic impregnated discs (Himedia, India) of $8 \mathrm{~mm}$ diameter were used for the test. Around 24 hours old culture from nutrient broth was swabbed across the surface of dried plates of MHA (Muller Hinton Agar, Himedia, India) using sterile cotton swabs. The plates were left to dry for 10 minutes and then the discs were placed on surface dried MHA plates sufficiently separated from each other ( 7 discs in a single plate at distance $>24 \mathrm{~mm}$ ). A total of 14 antibiotic discs which included Amoxyclav (AMC) - $10 \mu \mathrm{g}$, Cefotaxime (CTX) - $30 \mu \mathrm{g}$, Chloramphenicol (C) - $10 \mu \mathrm{g}$, Ciprofloxacin (CIP) $-5 \mu \mathrm{g}$, Colistin (CL) $-10 \mu \mathrm{g}$, Cotrimoxazole (COT) $-25 \mu \mathrm{g}$, 
Doxycycline hydrochloride (DO) - $10 \mu \mathrm{g}$, Erythromycin (E) $-15 \mu \mathrm{g}$, Gentamycin (GEN) - $10 \mu \mathrm{g}$, Meropenem (MRP) $-10 \mu \mathrm{g}$, Nitrofurantoin (NIT) $-100 \mu \mathrm{g}$, Penicillin (P) $-10 \mu \mathrm{g}$, Streptomycin (ST) $-10 \mu \mathrm{g}$ and Tetracycline (TET) $-30 \mu \mathrm{g}$ were used. After overnight incubation at $37^{\circ} \mathrm{C}$, the inhibition zone was measured and compared with the standard Hi-Media interpretation chart based on recommendations of Clinical Laboratory Standards Institute (CLSI, 2015) and classified as Resistant, Intermediate and Susceptible. The MAR index value of the isolates was calculated by taking the ratio of the number of antibiotics to which the isolate is resistant to the total number of antibiotics to which the isolate is exposed (Krumperman, 1983).

\section{Phenotypic virulence screening}

The isolated $V$. parahaemolyticus strains were further screened for their virulence potential by verifying the phenotypic production of extracellular virulence enzymes. The enzymes screened were amylase, gelatinase, lipase, phospholipase, hemolysin ( $\beta$-hemolysis) and urease. $\beta$-hemolysis (Kanagawa phenomenon) test was done on Wagatsuma blood agar (Himedia, India) (Su and Lee, 1997). Plate assay was used for all the enzymes except for urease which was screened by tube test. Enzyme screening methods previously described in Silvester et al. (2017) were followed.

\section{Statistical analyses}

IBM SPSS version 22 (IBM Corporation, New York, USA) was used for the analysis. Pearson's Chi-squared test was applied to test significant differences in the prevalence of antibiotic resistance and extracellular enzymes among isolates from various sources. Statistical significance level was set at $5 \%$.

\section{Results}

Isolation of $V$. parahaemolyticus from shrimp and crab samples

$V$. parahaemolyticus was present in all the tested shrimp and crab samples $(\mathrm{n}=42)$. Those isolates which produced $V$. parahaemolyticus specific bluish-greencoloured colonies on HiCrome ${ }^{\mathrm{TM}}$ Vibrio agar and gave positive amplification for species-specific tox $R$ gene were confirmed as $V$. parahaemolyticus. It is to be noted that all the isolates which gave species-specific coloured colonies on HiCrome agar were positive for tox $R$ gene, thus indicating the efficacy of the chromogenic media for accurate identification of the species. Further, 16S rRNA sequence of TC7 strain exhibited $99.46 \%$ identity to $16 \mathrm{~S}$ rRNA sequence of $V$. parahaemolyticus strain GH289 (id: MG593218.1) present in the GenBank database thus confirming our strain to be $V$. parahaemolyticus. The sequence of TC7 was submitted and allotted with a GenBank accession number MW326758.

Among the shrimp samples 60 isolates out of 72 pre- sumptive colonies $(85 \% ; 18$ isolates from Munambam, 30 isolates from Varapuzha and 12 from Thoppumpady) were $V$. parahaemolyticus. Similarly, 53 out of 86 isolates from crab samples $(61.6 \%$; 9 isolates from $\mathrm{Mu}-$ nambam, 28 from Varapuzha and 16 from Thoppumpady) were found to be $V$. parahaemolyticus. Overall, 113 $V$. parahaemolyticus were isolated from the tested samples, among which highest prevalence was observed in samples collected from Varapuzha (51.3\%).

Prevalence of antibiotic resistance among $V$. parahaemolyticus isolates from crab

Table 1 gives the percentage of antibiotic resistance among the crab isolates from the three stations. Majority of the $V$. parahaemolyticus strains (94\%) from crabs were multiple drug resistant (MDR). Thoppumpady isolates showed $100 \%$ resistance to three of the antibiotics namely AMC, CTX and P and 68.75\% were resistant towards ST. They were completely sensitive to six of the total antibiotics used; C, CL, COT, DO, NIT and TET. Isolates obtained from Munambam station showed complete resistance $(100 \%)$ to $\mathrm{P}, 77.8 \%$ and $66.6 \%$ were resistant to ST and CTX respectively. All the isolates $(100 \%)$ tested from this station showed susceptibility to six of the antibiotics namely C, CL, COT, DO, NIT and TET. All strains isolated from Varapuzha showed resistance towards AMC, CTX, P and ST. One hundred percent sensitivity was shown by the strains towards six of the antibiotics, namely C, CL, COT, DO, NIT and TET. By comparing the results, we could conclude that all the isolated strains of $V$. parahaemolyticus from all the three stations were completely sensitive to six of the drugs: C, CL, COT, DO, NIT and TET. Few strains showed varying degrees of intermediate resistance to few of the drugs tested (Table 1).

The MAR index of isolates ranged from 0.21 to 0.43. Comparing between the stations, the MAR index of Thoppumpady isolates ranged from 0.21 to 0.36 , that of Munambam ranged from 0.21 to 0.43 and from Varapuzha ranged from 0.29 to 0.43 . From the present study, a total of ten different antibiotic resistance patterns were obtained among isolates from crab samples. Majority of the isolates were resistant to 3 or more antibiotics. Quadruple resistance was exhibited by about $70 \%$ of the isolates $(n=37)$. Few isolates showed resistance to five, six, or even seven antibiotics $(n=7)$. AMC, CTX, P, ST $(n=20)$ was the most repeated antibiotic resistance phenotype pattern observed followed by AMC, CTX, E, P, $\mathrm{ST}(\mathrm{n}=8)$ and AMC, CTX, E, MRP, P, ST $(n=6)$.

Prevalence of antibiotic resistance among $V$ p parahaemolyticus isolates from shrimp

Table 2 represents the percentage of antibiotic resistance among the shrimp isolates from three stations. All the $V$. parahaemolyticus isolates from shrimp were found to be multiple drug resistant. The isolates from Thoppumpady were resistant to AMC, CTX and P, and sensitive towards C, NIT and TET. A high percentage (83.3\%) 
of resistance was also exhibited towards ST and CL. Isolates from Munambam showed 100\% resistance to AMX, CTX, P and ST. The isolates were $100 \%$ sensitive towards C, CL, COT, DO, NIT and TET. A high percentage of resistance was also exhibited towards MRP (83.3\%). The isolates from Varapuzha showed 100\% resistance to the antibiotics AMC, CTX, MRP and P. High level of resistance $(83.3 \%)$ was observed towards ST also. The isolates were highly sensitive to NIT $(100 \%)$ and CIP $(83.3 \%)$. Thus, we found that all the shrimp isolates from three stations showed resistance to AMC, CTX and P and all were sensitive to NIT.

The overall MAR index of the isolates from the three sampling stations ranged from to 0.28 to 0.57 ; Munambam $0.28-0.42$, Varapuzha $0.35-0.57$ and Thoppumpady $0.28-0.57$. All the isolates showed resistance to 3 or more antibiotics thus revealing them to be multi-drug resistant. A total of 11 different antibiotic resistant phenotypes were observed among shrimp isolates. The most repeated antibiotic resistance pattern observed among the isolates was AMC, CTX, E, MRP, P, ST (n=16) followed by AMC, E, MRP, P, ST $(\mathrm{n}=6)$ and AMC, CTX, CL, P, ST $(n=6)$.

\section{Phenotypic virulence enzyme screening}

Extracellular virulence enzyme profiling revealed that majority of the isolates produced most of the virulence enzymes. The most potential virulence phenotypes of $V$. parahaemolyticus were hemolysin, lipase, amylase and phospholipase production, from both crab and shrimp samples (Figure 2). Urease and gelatinase production were the least expressed phenotypes from both the samples. The Kanagawa phenomenon ( $\beta$-hemolysis) was observed in almost all the strains from both shrimp and crabs. This confirms the presence of $t d h$ (thermostable direct hemolysin) gene in the $V$. parahaemolyticus isolates because only TDH protein induces beta-hemolysis in Wagatsuma medium. There was significant difference in hemolysin, gelatinase and phospholipase production among isolates from crab and shrimp samples $(\mathrm{P}<0.05)$ (Figure 2). However, there was no significant difference in lipase, urease and amylase production $(\mathrm{P}>0.05)$. The extracellular enzyme profile of the $V$. parahaemolyticus from crab showed the following dominance pattern: hemolysin $>$ lipase $>$ phospholipase $>$ am ylase $>$ gelatinase $>$ urease. The isolates from shrimp exhibited the following extracellular enzyme profile: hemolysin $>$ amylase $>$ lipase $>$ phospholipase $>$ gelatinase $=$ urease.

Table 1. Antibiotic resistance profiles of $V$. parahaemolyticus isolates from crab samples represented in percentage as Resistant (R), Intermediate (I), Susceptible (S)

\begin{tabular}{|c|c|c|c|c|c|c|c|c|c|c|}
\hline \multirow{2}{*}{ Antibiotics } & \multicolumn{3}{|c|}{$\begin{array}{l}\text { Thoppumpady }(\%) \\
(\mathrm{n}=16)\end{array}$} & \multicolumn{3}{|c|}{$\begin{array}{l}\text { Munambam }(\%) \\
(n=9)\end{array}$} & \multicolumn{3}{|c|}{$\begin{array}{l}\text { Varapuzha }(\%) \\
(\mathrm{n}=28)\end{array}$} & \multirow{2}{*}{ P-value } \\
\hline & $\begin{array}{l}\mathrm{R} \\
(\%)\end{array}$ & $\begin{array}{c}\mathrm{I} \\
(\%)\end{array}$ & $\begin{array}{c}\mathrm{S} \\
(\%)\end{array}$ & $\begin{array}{l}\mathrm{R} \\
(\%)\end{array}$ & $\begin{array}{c}\text { I } \\
(\%)\end{array}$ & $\begin{array}{c}\mathrm{S} \\
(\%)\end{array}$ & $\begin{array}{l}\mathrm{R} \\
(\%)\end{array}$ & $\begin{array}{c}\mathrm{I} \\
(\%)\end{array}$ & $\begin{array}{c}\mathrm{S} \\
(\%)\end{array}$ & \\
\hline AMC 10 & $\begin{array}{c}16 \\
(100)\end{array}$ & 0 & 0 & $\begin{array}{c}5 \\
(55)\end{array}$ & $\begin{array}{c}4 \\
(45)\end{array}$ & 0 & $\begin{array}{c}28 \\
(100)\end{array}$ & 0 & 0 & .000 \\
\hline CTX 30 & $\begin{array}{c}16 \\
(100)\end{array}$ & 0 & 0 & $\begin{array}{c}6 \\
(67)\end{array}$ & $\begin{array}{c}3 \\
(33)\end{array}$ & 0 & $\begin{array}{c}28 \\
(100)\end{array}$ & 0 & 0 & .000 \\
\hline C 10 & 0 & 0 & $\begin{array}{c}16 \\
(100)\end{array}$ & 0 & 0 & $\begin{array}{c}9 \\
(100)\end{array}$ & 0 & 0 & $\begin{array}{c}28 \\
(100)\end{array}$ & - \\
\hline CIP 5 & 0 & $\begin{array}{c}16 \\
(100)\end{array}$ & 0 & 0 & $\begin{array}{c}5 \\
(55)\end{array}$ & $\begin{array}{c}4 \\
(45)\end{array}$ & 0 & $\begin{array}{c}28 \\
(100)\end{array}$ & 0 & - \\
\hline CL 10 & 0 & 0 & $\begin{array}{c}16 \\
(100)\end{array}$ & 0 & 0 & $\begin{array}{c}9 \\
(100)\end{array}$ & 0 & 0 & 100 & - \\
\hline COT 25 & 0 & 0 & $\begin{array}{c}16 \\
(100)\end{array}$ & 0 & 0 & $\begin{array}{c}9 \\
(100)\end{array}$ & 0 & 0 & 100 & - \\
\hline DO 10 & 0 & 0 & $\begin{array}{c}16 \\
(100)\end{array}$ & 0 & 0 & $\begin{array}{c}9 \\
(100)\end{array}$ & 0 & 0 & 100 & - \\
\hline E 15 & $\begin{array}{c}8 \\
(50)\end{array}$ & 50 & 0 & $\begin{array}{c}3 \\
(33)\end{array}$ & $\begin{array}{c}6 \\
(67)\end{array}$ & 0 & $\begin{array}{c}9 \\
(33)\end{array}$ & $\begin{array}{c}19 \\
(67)\end{array}$ & 0 & .017 \\
\hline GEN 10 & $\begin{array}{c}3 \\
(19)\end{array}$ & $\begin{array}{c}8 \\
(50)\end{array}$ & $\begin{array}{c}5 \\
(31)\end{array}$ & 0 & $\begin{array}{c}5 \\
(55)\end{array}$ & $\begin{array}{c}4 \\
(45)\end{array}$ & $\begin{array}{c}5 \\
(17)\end{array}$ & $\begin{array}{c}19 \\
(67)\end{array}$ & $\begin{array}{c}4 \\
14\end{array}$ & .000 \\
\hline MRP 10 & $\begin{array}{c}5 \\
(31)\end{array}$ & $\begin{array}{c}11 \\
(69)\end{array}$ & 0 & $\begin{array}{c}3 \\
(33)\end{array}$ & $\begin{array}{c}6 \\
(67)\end{array}$ & 0 & $\begin{array}{c}9 \\
(33)\end{array}$ & $\begin{array}{c}19 \\
(67)\end{array}$ & 0 & - \\
\hline NIT 100 & 0 & 0 & $\begin{array}{c}16 \\
(100)\end{array}$ & 0 & 0 & $\begin{array}{c}9 \\
(100)\end{array}$ & 0 & 0 & $\begin{array}{c}28 \\
(100)\end{array}$ & - \\
\hline P 10 & $\begin{array}{c}16 \\
(100)\end{array}$ & 0 & 0 & $\begin{array}{c}9 \\
(100)\end{array}$ & 0 & 0 & $\begin{array}{c}28 \\
(100)\end{array}$ & 0 & 0 & - \\
\hline ST 30 & $\begin{array}{c}11 \\
(69)\end{array}$ & $\begin{array}{c}5 \\
(31)\end{array}$ & 0 & $\begin{array}{c}7 \\
(78)\end{array}$ & 0 & $\begin{array}{c}2 \\
(22)\end{array}$ & $\begin{array}{c}28 \\
(100)\end{array}$ & 0 & 0 & .000 \\
\hline TET 30 & 0 & 0 & $\begin{array}{c}16 \\
(100)\end{array}$ & 0 & 0 & $\begin{array}{c}9 \\
(100)\end{array}$ & 0 & 0 & $\begin{array}{c}28 \\
(100)\end{array}$ & - \\
\hline
\end{tabular}


Table 2. Antibiotic resistance profiles of $V$. parahaemolyticus isolates from shrimp samples represented in percentage as Resistant (R), Interme-

\begin{tabular}{|c|c|c|c|c|c|c|c|c|c|c|}
\hline \multirow{2}{*}{ Antibiotics } & \multicolumn{3}{|c|}{$\begin{array}{l}\text { Thoppumpady (\%) } \\
(\mathrm{n}=12)\end{array}$} & \multicolumn{3}{|c|}{$\begin{array}{c}\text { Munambam }(\%) \\
(\mathrm{n}=18)\end{array}$} & \multicolumn{3}{|c|}{$\begin{array}{l}\text { Varapuzha }(\%) \\
\qquad(\mathrm{n}=30)\end{array}$} & \multirow{2}{*}{ P-value } \\
\hline & $\begin{array}{l}\mathrm{R} \\
(\%)\end{array}$ & $\begin{array}{c}\mathrm{I} \\
(\%)\end{array}$ & $\begin{array}{c}\mathrm{S} \\
(\%)\end{array}$ & $\begin{array}{l}\mathrm{R} \\
(\%)\end{array}$ & $\begin{array}{c}\mathrm{I} \\
(\%)\end{array}$ & $\begin{array}{c}\mathrm{S} \\
(\%)\end{array}$ & $\begin{array}{l}\mathrm{R} \\
(\%)\end{array}$ & $\begin{array}{c}\mathrm{I} \\
(\%)\end{array}$ & $\begin{array}{c}\mathrm{S} \\
(\%)\end{array}$ & \\
\hline AMC 10 & $\begin{array}{c}12 \\
(100)\end{array}$ & 0 & 0 & $\begin{array}{c}18 \\
(100)\end{array}$ & 0 & 0 & $\begin{array}{c}30 \\
(100)\end{array}$ & 0 & 0 & - \\
\hline CTX 30 & $\begin{array}{c}12 \\
(100)\end{array}$ & 0 & 0 & $\begin{array}{c}18 \\
(100)\end{array}$ & 0 & 0 & $\begin{array}{c}30 \\
(100)\end{array}$ & 0 & 0 & - \\
\hline C 10 & 0 & 0 & $\begin{array}{c}12 \\
(100)\end{array}$ & 0 & 0 & $\begin{array}{c}18 \\
(100)\end{array}$ & 0 & $\begin{array}{c}20 \\
(67)\end{array}$ & $\begin{array}{c}10 \\
(33)\end{array}$ & - \\
\hline CIP 5 & $\begin{array}{c}2 \\
(17)\end{array}$ & $\begin{array}{c}10 \\
(83)\end{array}$ & 0 & 0 & $\begin{array}{c}15 \\
(83)\end{array}$ & $\begin{array}{c}3 \\
(17)\end{array}$ & $\begin{array}{c}5 \\
(17)\end{array}$ & $\begin{array}{c}25 \\
(83)\end{array}$ & 0 & .000 \\
\hline CL 10 & $\begin{array}{c}10 \\
(83)\end{array}$ & 0 & $\begin{array}{c}2 \\
(17)\end{array}$ & 0 & 0 & $\begin{array}{c}18 \\
(100)\end{array}$ & $\begin{array}{c}15 \\
(50)\end{array}$ & 0 & $\begin{array}{c}15 \\
(50)\end{array}$ & .000 \\
\hline COT 25 & 0 & $\begin{array}{c}2 \\
(17)\end{array}$ & $\begin{array}{c}10 \\
(83)\end{array}$ & 0 & 0 & $\begin{array}{c}18 \\
(100)\end{array}$ & 0 & $\begin{array}{c}10 \\
(33)\end{array}$ & $\begin{array}{c}20 \\
(67)\end{array}$ & - \\
\hline DO 10 & 0 & $\begin{array}{c}2 \\
(17)\end{array}$ & $\begin{array}{c}10 \\
(83)\end{array}$ & 0 & $\begin{array}{c}3 \\
(17)\end{array}$ & $\begin{array}{c}15 \\
(83)\end{array}$ & 0 & $\begin{array}{c}10 \\
(33)\end{array}$ & $\begin{array}{c}20 \\
(67)\end{array}$ & - \\
\hline E 15 & $\begin{array}{c}6 \\
(50)\end{array}$ & $\begin{array}{c}6 \\
(50)\end{array}$ & 0 & $\begin{array}{c}6 \\
(33)\end{array}$ & $\begin{array}{c}12 \\
(67)\end{array}$ & 0 & $\begin{array}{c}15 \\
(50)\end{array}$ & $\begin{array}{c}15 \\
(50)\end{array}$ & 0 & 0.20 \\
\hline GEN 10 & 0 & $\begin{array}{c}10 \\
(83)\end{array}$ & $\begin{array}{c}2 \\
(17)\end{array}$ & 0 & $\begin{array}{c}18 \\
(100)\end{array}$ & 0 & 0 & $\begin{array}{c}20 \\
(67)\end{array}$ & $\begin{array}{c}10 \\
(33)\end{array}$ & - \\
\hline MRP 10 & $\begin{array}{c}6 \\
(50)\end{array}$ & $\begin{array}{c}6 \\
(50)\end{array}$ & 0 & $\begin{array}{c}15 \\
(83)\end{array}$ & $\begin{array}{c}3 \\
(17)\end{array}$ & 0 & $\begin{array}{c}30 \\
(100)\end{array}$ & 0 & 0 & .000 \\
\hline NIT 100 & 0 & 0 & $\begin{array}{c}12 \\
(100)\end{array}$ & 0 & 0 & $\begin{array}{c}18 \\
(100)\end{array}$ & 0 & 0 & $\begin{array}{c}30 \\
(100)\end{array}$ & - \\
\hline P 10 & $\begin{array}{c}12 \\
(100)\end{array}$ & 0 & 0 & $\begin{array}{c}18 \\
(100)\end{array}$ & 0 & 0 & $\begin{array}{c}30 \\
(100)\end{array}$ & 0 & 0 & - \\
\hline ST 30 & $\begin{array}{c}10 \\
(83)\end{array}$ & $\begin{array}{c}2 \\
(17)\end{array}$ & 0 & $\begin{array}{c}18 \\
(100)\end{array}$ & 0 & 0 & $\begin{array}{c}25 \\
(83)\end{array}$ & $\begin{array}{c}5 \\
(17)\end{array}$ & 0 & .000 \\
\hline TET 30 & 0 & 0 & $\begin{array}{c}12 \\
(100)\end{array}$ & 0 & 0 & $\begin{array}{c}18 \\
(100)\end{array}$ & 0 & $\begin{array}{c}15 \\
(50)\end{array}$ & $\begin{array}{c}15 \\
(50)\end{array}$ & - \\
\hline
\end{tabular}

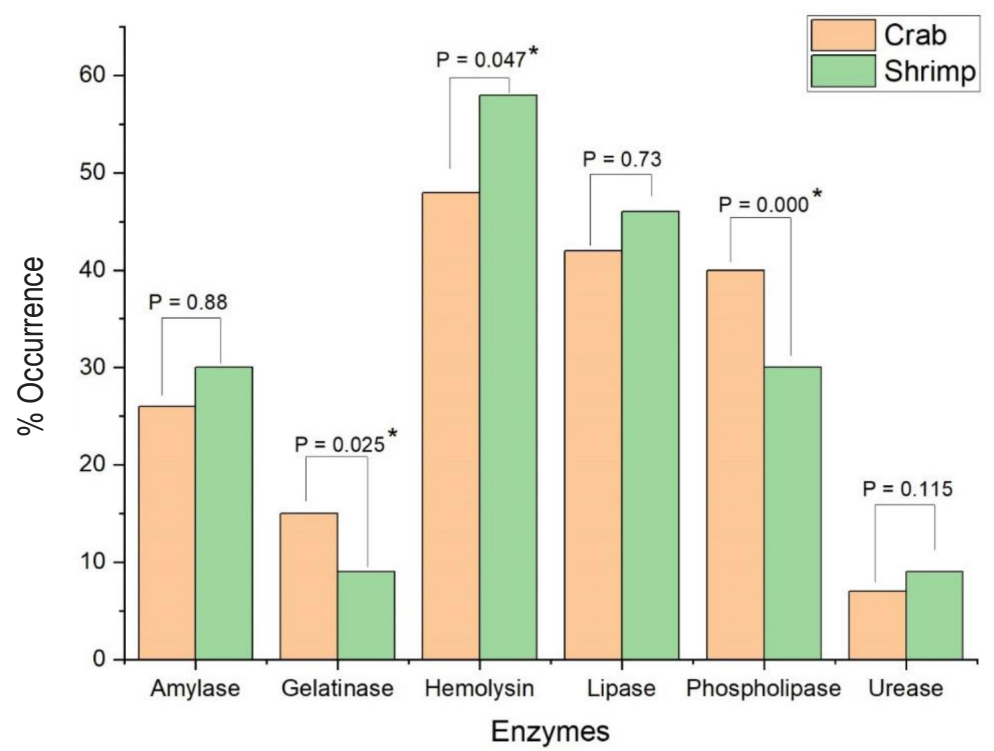

Figure 2. Graph showing the relative extracellular virulence enzyme production among V. parahaemolyticus strains from crab and shrimp samples 


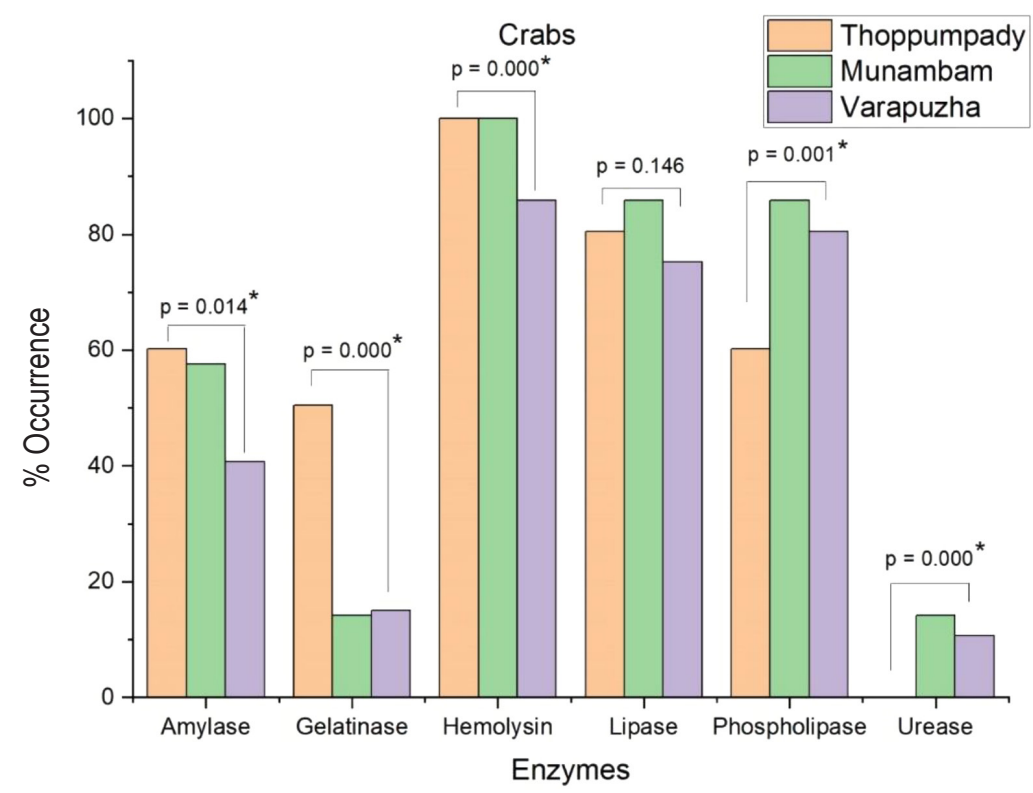

Figure 3. Graph showing the percentage of extracellular enzyme production of $V$. parahaemolyticus strains from crab samples

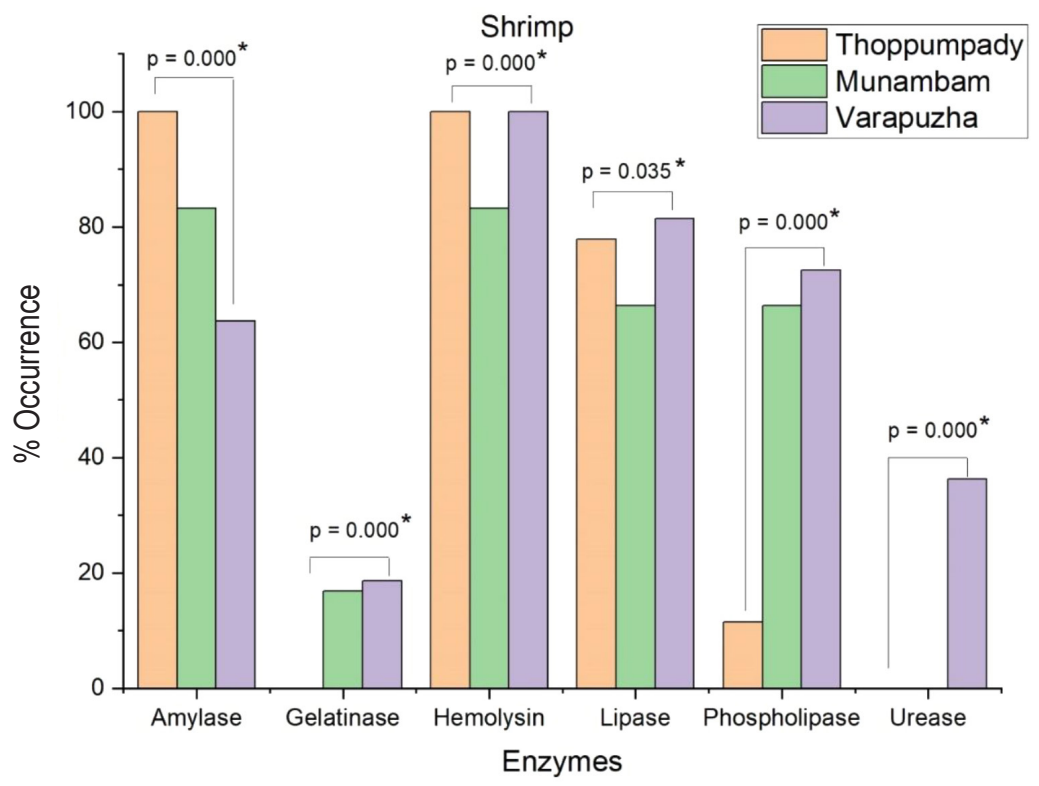

Figure 4. Graph showing the percentage of extracellular enzyme production of $V$. parahaemolyticus strains from shrimp samples

Comparing the station-wise enzyme production, a significant difference was observed in production of all enzymes $(\mathrm{P}<0.05)$ except lipase among crab isolates (Figure 3). Similarly, a significant difference was observed between shrimp isolates from three stations $(\mathrm{P}<0.05)$ (Figure 4). Hemolysin producers dominated in shrimps and crabs from Varapuzha and the least produced was gelatinase and urease. All the shrimp isolates from Thoppumpady produced amylase and hemolysin and all crab isolates produced hemolysin. Urease producing isolates were absent in samples from this station. Among the $\mathrm{Mu}-$ nambam isolates, all from the crabs and majority from shrimp produced hemolysin. Urease producers were least expressed among crab samples and absent among shrimp samples.

\section{Discussion}

In the present study, $V$. parahaemolyticus was detected in all the shrimp and crab samples (100\%) collected from major fish markets in Cochin. In a previous study on finfish and shellfish collected from Cochin during the year $2015-16,90 \%$ of the samples were positive for $V$. parahaemolyticus (Narayanan et al., 2020). Whereas in another study on shellfishes collected from 
the same study area during $2010-11$, only $68 \%$ samples harboured $V$. parahaemolyticus (Sudha et al., 2014). This clearly shows that the incidence of the pathogen has increased over these years. In a study from Malaysia, 44\% of the shellfish samples collected was contaminated with V. parahaemolyticus (Letchumanan et al., 2015). Tran et al. (2018) reported that $86.2 \%$ of the seafood samples collected from Vietnam were found to be positive for $V$. parahaemolyticus. In a recent study from China, $V$. parahaemolyticus was isolated from fresh aquatic products including 19 species of shellfish, 2 species of crustaceans, and 2 species of fishes collected from Shanghai fish markets (Su and Chen, 2020).

The rise in multiple antibiotic resistance and antibiotic resistance genes (ARGs) among pathogenic vibrios in seafood is a threat to the public health. This poses a serious health risk as the seafood may act as vehicles for transmission of resistant strains from environment to consumers via ingestion of contaminated food. In the present study, majority of the $V$. parahaemolyticus strains isolated from seafoods exhibited multi-drug resistance. The MAR index of the isolates from shrimp samples ranged from 0.28 to 0.57 and those from crab ranged from 0.25 to 0.43 . MAR index $>0.2$ is said to be originated from high risk sources of contamination. The antibiotics usually recommended for Vibrio infections are cephalothin, cefuroxime, cefotaxime, ceftazidime, tetracycline, doxycycline, fluoroquinolone, amikacin, gentamicin and trimethoprim-sulfamethoxazole (CDC, 2013; Letchumanan et al., 2015). All the shrimp isolates from three stations exhibited resistance to amoxyclav, cefotaxime and penicillin and all were sensitive to nitrofurantoin. Our results are in agreement with previous reports stating that $V$. parahaemolyticus is becoming resistant toward third and fourth generation cephalosporins (Narayanan et al., 2020; Park et al., 2018; Vaseeharan et al., 2005; Yu et al., 2016). In our study in 2015, all V. parahaemolyticus isolates from shrimp farms along the Cochin estuary demonstrated sensitivity towards streptomycin, gentamicin and netillin and a high percentage of resistance was also observed towards beta lactams, sulphamethoxazole and erythromycin and low-level resistance to nitrofurantoin (Silvester et al., 2015). However, in the present study, a high level of resistance was observed towards streptomycin and complete sensitivity to nitrofurantoin, thereby clearly indicating a change in the antibiotic resistance pattern. In another recent study from Malaysia V. parahaemolyticus isolates displayed high levels of resistance to ampicillin, cefazolin, and penicillin, as well as intermediate levels of resistance to cefotaxime and ciprofloxacin (Tan et al., 2020). In a study from Palk Bay, the Vibrio isolates exhibited resistance towards beta-lactams, vancomycin, nitrofurantoin, gentamicin, azithromycin, oxytetracycline, tetracycline and chloramphenicol (Sneha et al., 2016). A rising trend is observed in the presence of multi-drug resistant $V$. parahaemolyticus from aquatic origin (Xie et al., 2016). Multiple drug resistant V. parahaemolyticus was previously isolated from fish landing centers and retail markets from South India (Reyhanath and Kutty, 2014; Sudha et al., 2014). All Vibrio isolates from previous study were susceptible towards chloramphenicol, tetracycline and nalidixic acid (Sudha et al., 2014). The isolates from our study areas showed high level of susceptibility towards chloramphenicol, co-trimoxasole (trimethoprimsulfamethoxazole), doxycycline, nitrofurantoin and tetracycline. These findings are in agreement with previous reports from various countries highlighting susceptibility of $V$. parahaemolyticus from shrimp and other seafoods towards chloramphenicol, cotrimoxazole, doxycyline, tetracyline (Letchumanan et al., 2015; Narayanan et al., 2020; Tan et al., 2020). Hence, these drugs could be used to treat $V$. parahaemolyticus infections from our area. Recent studies have highlighted the role of bacteriophages as potential antibiotic alternatives against vibrios (Letchumanan et al., 2016). Natural bacteriophages do not affect the health of fish or consumers. Phages pose significant advantages, such as being environmentally friendly and easily available in the environment and having greater host specificity and cheaper than antibiotics (Kalatzis et al., 2018).

Detection of exoenzymes in microorganisms isolated from foods represents a risk to the communities that consume the food because they tend to be more exposed to foodborne infections (Silva et al., 2018). Majority of the $V$. parahaemolyticus isolates in our study produced the virulence related exoezymes. This highlights the potential of the bacterium to turn into pathogenic under favorable conditions. The urease and hemolysin enzymes are considered the typical virulence markers for V. parahaemolyticus from clinical sources. Urea hydrolysis is known to be directly linked with the presence of trh gene and betahemolysis (Kanagawa) with presence of $t d h$ gene (Nair et al., 2007). Even though urease producers were least in our samples, hemolysin producers dominated in both shrimp and crab samples, revealing the presence of $t d h$ gene and virulence potential of the $V$. parahaemolyticus strains. This shows the capability of $V$. parahaemolyticus strains to cause beta-hemolysis of human erythrocytes, thereby posing a risk to consumers of these seafoods. In a previous study among $V$. parahaemolyticus from Cochin estuary, around $42.3 \%$ of the isolates produced hemolysin and $23.5 \%$ produced urease (Silvester et al., 2017). Lipases and phospholipases were also produced by our strains; these enzymes mainly contribute in nutrient acquisition and degrading the membrane lipid of the host, thus involving in the pathogen's virulence (Costa et al., 2013). The role of amylases and gelatinases in the human bacteremia also need to be confirmed (Vergis et al., 2002).

\section{Conclusion}

The study highlights the presence of multiple antibiotic resistant $V$. parahaemolyticus with virulence potential in the seafood samples. Further studies have to be conducted to screen the strains for the presence of various antibiotic resistant genes and also virulence genes such as $t d h$, trh, $t 3 s s$, t6ss etc. Our study reveals that seafoods may act as potential vehicle of transfer of antibi- 
otic resistant Vibrio to humans via ingestion of such contaminated food, thus risking consumer health. Though localised in nature these findings may have international significance since seafoods from our area are exported worldwide. In addition, it is to be noted that seafoods contaminated with banned antibiotics may lead to export rejection thus affecting our economy too. Surveillance and monitoring of the seafoods for multi-drug resistant Vibrio with virulence potential are needed on regular basis to guarantee the safety of the public health and for food security of the country.

\section{Acknowledgement}

The authors would like to thank Head, Dept. of Marine Biology, Microbiology and Biochemistry, CUSAT and $\mathrm{J}$ and $\mathrm{J}$ Biotech, Kerala, India for the facilities provided.

\section{Conflict of interest}

The authors declare that there is no potential conflict of interests.

\section{References}

Ahmed H.A., El Bayomi R.M., Hussein M.A., Khedr M.H.E., Abo Remela E.M., El-Ashram A.M.M. (2018). Molecular characterization, antibiotic resistance pattern and biofilm formation of Vibrio parahaemolyticus and $V$. cholerae isolated from crustaceans and humans. Int. J. Food. Microbiol., 274: 31-37.

Ananda Raja R., Sridhar R., Balachandran C., Palanisammi A., Ramesh S., Nagarajan K. (2017 a). Pathogenicity profile of Vibrio parahaemolyticus in farmed Pacific white shrimp, Penaeus vannamei. Fish Shell. Immunol., 67: 368-381.

Ananda Raja R., Sridhar R., Balachandran C., Palanisammi A., Ramesh S. Nagarajan K. (2017 b). Prevalence of Vibrio spp. with special reference to Vibrio parahaemolyticus in farmed penaeid shrimp Penaeus vannamei (Boone, 1931) from selected districts of Tamil Nadu, India. Indian J. Fish., 64: 122-128.

Ananda Raja R., Panigrahi A., De D., Kumar S. (2017 c). Investigations on white spot disease outbreak in Penaeus monodon (Fabricius, 1798) in association with Vibrio mimicus infection in the Sunderbans, West Bengal, India. Indian J. Fish., 64: 56.

Atlas R.M., Snyder J.W. (2013). Handbook of media for clinical and public health microbiology (1st ed.). CRC Press. https://doi.org/10.1201/ b15973

Bauer A.W., Kirby W.M.M., Sheris J.C., Turck M. (1966). Antibiotics susceptibility testing by standardized single disk method. Am. J. Clin. Pathol., 45: 493-496.

CDC (2013). Vibrio vulnificus: General information. In: National Center for Emerging and Zoonotic Infectious Diseases. DoF, Waterborne, and Environmental Disease, Editor.

CLSI (2015). Performance standards for antimicrobial disk susceptibility tests; Approved standard-eleventh edition M02-A12. Wayne, PA: Clinical and Laboratory Standards Institute, CLSI.

Costa R.A., Conde Amorim L.M.M., Araújo R.L., Fernandes Vieira R.H.S. (2013). Multiple enzymatic profiles of Vibrio parahaemolyticus strains isolated from oysters. Rev. Argent. Microbiol., 45: $267-270$.

Dash R.R. (2020). Livelihood assessment of the fishermen community of Jagatsinghpur district of Odisha, India. IJCRT, 8: 2320-2882.

Devi R., Surendran P.K., Chakraborty K. (2009). Antibiotic resistance and plasmid profiling of Vibrio parahaemolyticus isolated from shrimp farms along the coast of India. World. J. Microbiol. Biotechnol., 25: 2005-2012.

Elmahdi S., DaSilva L.V., Parveen S. (2016). Antibiotic resistance of Vibrio parahaemolyticus and Vibrio vulnificus in various countries: A review. Food. Microbiol., 57: 128-134.
Henson S., Saqib M., Rajasenan D. (2004). The impact of sanitary measures on exports of fishery products from India: The case of Kerala. Agriculture and Rural Development Department, World Bank.

Honda S., Goto I., Minematsu I., Ikeda N., Asano N., Ishibashi M., Kinoshita Y., Nishibuchi M., Honda,T., Miwatani T. (1987 a). Vibrio parahaemolyticus infectious disease caused by Kanagawa phenomenon-negative O3: K6 originated from Maldives. Japanese J. Infect. Dis., 61: 1070-1078.

Honda S., Goto I., Minematsu I., Ikeda N., Asano N., Ishibashi M., Kinoshita Y., Nishibuchi M., Honda T., Miwatani T. (1987 b). Gastroenteritis due to Kanagawa negative Vibrio parahaemolyticus. Lancet, 329: 331-332.

Humphries R.M., Linscott A.J. (2015). Practical guidance for clinical microbiology laboratories: Diagnosis of bacterial gastroenteritis. Clin. Microbiol. Rev., 28: 3-31.

Ina-Salwany M.Y., Al-Saari N., Mohamad A. (2019). Vibriosis in fish: a review on disease development and prevention. J. Aquat. Anim. Health., 31: 3-22.

Kalatzis P.G., Castillo D., Katharios P., Middelboe M. (2018). Bacteriophage interactions with marine pathogenic vibrios: Implications for phage therapy. Antibiotics, 7: 15.

Krumperman P.H. (1983). Multiple antibiotic resistance indexing of Escherichia coli to identify high-risk sources of fecal contamination of food. Appl. Environ. Microbiol., 46: 165-170.

Kulkarni P. (2005) The marine seafood export supply chain in India: Current state and influence of import requirements. International Institute for Sustainable Development. December, 2005.

Laxminarayan R., Chaudhury R.R. (2016). Antibiotic resistance in India: Drivers and opportunities for action. PLoS Med., 13: e1001974.

Letchumanan V., Chan K.G., Lee L.H. (2014). Vibrio parahaemolyticus: a review on the pathogenesis, prevalence, and advance molecular identification techniques. Front. Microbiol., 5: 705.

Letchumanan V., Yin W.F., Lee L.H., Chan K.G. (2015). Prevalence and antimicrobial susceptibility of Vibrio parahaemolyticus isolated from retail shrimps in Malaysia. Front. Microbiol., 6: 33.

Letchumanan V., Chan K., Pusparajah P., Saokaew S., Duangjai A., Goh Bey-H. (2016). Insights into bacteriophage application in controlling Vibrio species. Front. Microbiol., 7: 1114.

Malcolm T.T.H., Cheah Y.K., Radzi C.W.J.W.M., Kasim F.A (2015). Detection and quantification of pathogenic Vibrio parahaemolyticus in shellfish by using multiplex PCR and loop-mediated isothermal amplification assay. Food Cont., 47: 664-671.

Miranda C.D., Godoy F.A., Lee M.R. (2018). Current status of the use of antibiotics and the antimicrobial resistance in the Chilean salmon farms. Front. Microbiol., 9: 1284.

Nair G.B., Ramamurthy T., Bhattacharya S.K., Dutta B., Takeda Y., Sack D.A. (2007). Global dissemination of Vibrio parahaemolyticus serotype O3:K6 and its serovariants. Clin. Microbiol. Rev., 20: $39-48$.

Narayanan S.V., Joseph T.C., Peeralil S., Mothadaka M.P., Lalitha K.V. (2020). Prevalence, virulence characterization, AMR pattern and genetic relatedness of Vibrio parahaemolyticus isolates from retail seafood of Kerala, India. Front. Microbiol., 11: 592.

Park K., Mok J.S., Kwon J.Y., Ryu AR., Kim S.H., Lee H.J. (2018). Food-borne outbreaks, distributions, virulence, and antibiotic resistance profiles of Vibrio parahaemolyticus in Korea from 2003 to 2016: a review. Fish. Aquatic. Sci., 21: 3.

Pazhani G.P., Bhowmik S.K., Ghosh S., Guin S., Dutta S., Rajendran K., Saha D.R., Nandy R.K., Bhattacharya M.K., Mukhopadhyay A.K., Ramamurthy T. (2014). Trends in the epidemiology of pandemic and non-pandemic strains of Vibrio parahaemolyticus isolated from diarrheal patients in Kolkata, India. PLOS Negelct. Trop. D., 8: 2815.

Reyhanath P.V., Kutty R. (2014). Incidence of multidrug resistant Vibrio parahaemolyticus isolated from Ponnani, South India. Iran. J. Microbiol., 6: 60-67.

Rico A., Satapornvanit K., Haque M.M. (2012). Use of chemicals and biological products in Asian aquaculture and their potential environmental risks: a critical review. Rev. Aqua., 4: 75-93.

Silva I.P., Carneiro C.S., Saraiva M.A.F., Oliveira T.A.S., Sousa O.V., 
Evangelista Barreto N.S. (2018). Antimicrobial resistance and potential virulence of Vibrio parahaemolyticus isolated from water and bivalve mollusks from Bahia, Brazil. Mar. Pollut. Bull., 131: 757-762.

Silvester R., Alexander D., Ammanamveetil M.H.A. (2015). Prevalence, antibiotic resistance, virulence and plasmid profiles of Vibrio parahaemolyticus from a tropical estuary and adjoining traditional prawn farm along the southwest coast of India. Ann. Microbiol., 65: 2141-2149.

Silvester R., Madhavan A., Antony A., Alexander D., Francis., Hatha M. (2017). Genotyping and distribution of virulence factors in $V$. parahaemolyticus from seafood and environmental sources, South-west coast of India. Reg. Stud. Mar. Sci., 12: 64-72.

Sneha K.G., Anas A., Jayalakshmy K.V., Jasmin C., Vipin Das P.V., Pai S.S., Pappu S., Nair M., Muraleedharan K.R., Sudheesh K., Nair S. (2016). Distribution of multiple antibiotic resistant Vibrio spp. across Palk Bay. Reg. Stud. Mar. Sci., 3: 242-250.

Statistical Year Book India (2017). Ministry of Statistics and Program Implementation Government of India.

Su S.C., Lee C.Y. (1997) Characterization of haemolysis of the Vibrio parahaemolyticus. Chin. J. Microbiol. Immunol., 30: 32-42.

Su C., Chen L. (2020). Virulence, resistance, and genetic diversity of Vibrio parahaemolyticus recovered from commonly consumed aquatic products in Shanghai, China. Mar. Poll. Bullet., 160: 111554.

Sudha S., Mridula C., Silvester R., Hatha A.A. (2014). Prevalence and antibiotic resistance of pathogenic vibrios in shellfishes from Cochin market. Indian. J. Geo. Mar. Sci., 43: 815-824.

Tan L.T., Lee L., Goh B. (2020). Critical review of fermentation and extraction of anti-Vibrio compounds from Streptomyces. Prog. Microbes. Mol. Biol., 3: a0000051.

Tran T.H.T., Yanagawa H., Nguyen K.T., Hara-Kudo Y., Taniguchi T.,
Hayashidani H. (2018). Prevalence of Vibrio parahaemolyticus in seafood and water environment in the Mekong Delta, Vietnam. J. Veter. Med. Sci., 80: 1737-1742.

Van Boeckel T.P., Gandra S., Ashok A., Caudron Q., Grenfell B.T., Levin S.A., Laxminarayan R. (2014). Global antibiotic consumption 2000 to 2010: an analysis of national pharmaceutical sales. Lancet. Infect. Dis., 14: 742-750.

Vaseeharan B., Ramasamy P., Murugan T., Chen J.C. (2005). In vitro susceptibility of antibiotics against Vibrio spp. and Aeromonas spp. isolated from Penaeus monodon hatcheries and ponds. Int. J. Antimicrob. Agents., 26: 285-291.

Vergis E.N., Shankar N., Chow J.W., Hayden M.K., Snydman D.R., Zervos M.J., Linden P.K., Wagener M.M., Muder R.R. (2002). Association between the presence of enterococcal virulence factors gelatinase, hemolysin, and enterococcal surface protein and mortality among patients with bacteremia due to Enterococcus faecalis. Clin. Infect. Dis., 35: 570-575.

Xie T., Wu Q., Zhang J., Xu., Cheng J. (2016). Comparison of Vibrio parahaemolyticus isolates from aquatic products and clinical by antibiotic susceptibility, virulence, and molecular characterisation. Food. Cont., 71: 315-32.

Yano Y., Hamano K., Satomi M., Tsutsui I., Ban M., Aue-umneoy D. (2014). Prevalence and antimicrobial susceptibility of Vibrio species related to food safety isolated from shrimp cultured at inland ponds in Thailand. Food. Cont., 38: 30-45.

Yu Q., Niu M., Yu M., Liu Y., Wang D., Shi X. (2016). Prevalence and antimicrobial susceptibility of Vibrio parahaemolyticus isolated from retail shellfish in Shanghai. Food. Cont., 60: 263-268.

Received: 13 IV 2021

Accepted: 22 IX 2021 